\title{
Oceanography
}

CITATION

Vardaro, M.F., and J. McDonnell. 2018. Accessing OOI data. Oceanography 31(1):36-37, https://doi.org/10.5670/oceanog.2018.106.

$\mathrm{DOI}$

https://doi.org/10.5670/oceanog.2018.106

COPYRIGHT

This article has been published in Oceanography, Volume 31, Number 1, a quarterly journal of The Oceanography Society. Copyright 2018 by The Oceanography Society. All rights reserved.

USAGE

Permission is granted to copy this article for use in teaching and research. Republication, systematic reproduction, or collective redistribution of any portion of this article by photocopy machine, reposting, or other means is permitted only with the approval of The Oceanography Society. Send all correspondence to: info@tos.org or The Oceanography Society, PO Box 1931, Rockville, MD 20849-1931, USA. 

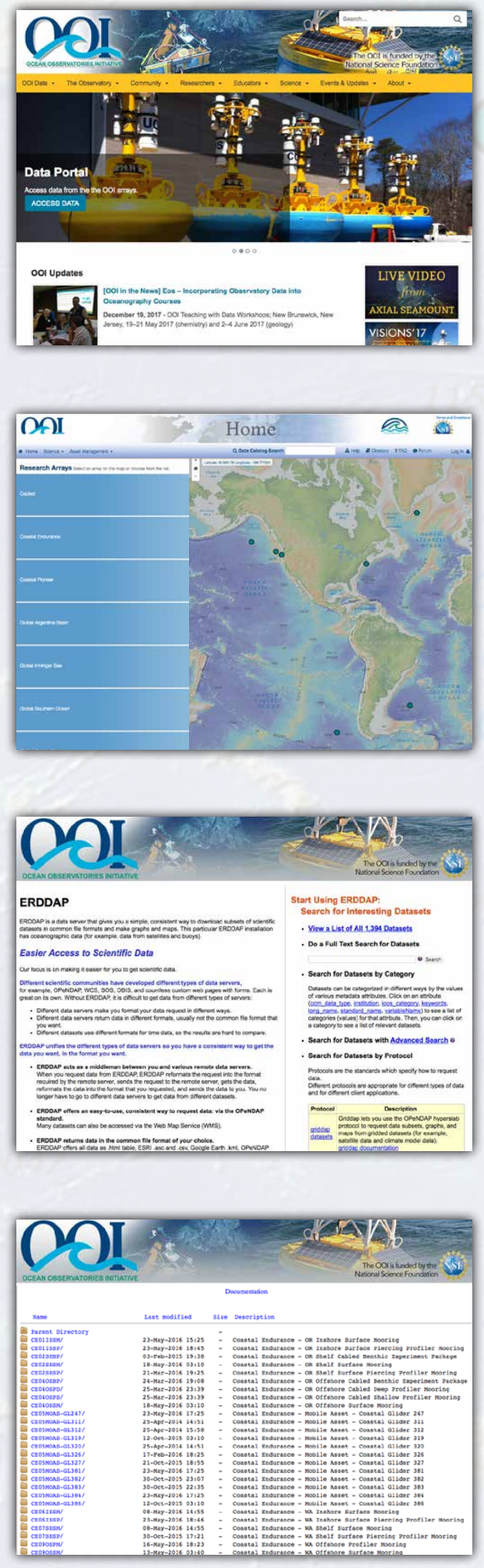

\section{Ocean Observatories Initiative}

http://oceanobservatories.org

The Ocean Observatories Initiative (OOI) website is the main website for the project. It highlights the science themes, platforms, and instrumentation of the OOI project. It also serves as a hub to access the other OOI sites.

Key Features:

- Events and updates

- Background on science themes

- Explanation of instrumentation and technology

- Information for researchers

- Links to data portal, cruise data, and analytical data pages

\section{OOI Data Portal}

https://ooinet.oceanobservatories.org

The data portal facilitates access to OOI data for research and education.

Key Features:

- List of OOI sites and platforms, including location and depth information

- Quick looks at data streams

- Ability to plot and download a data set and associated metadata (NetCDF, .csv, .json format)

\section{OOI ERDDAP Server}

https://erddap-uncabled.oceanobservatories.org/uncabled

A data server that provides a simple, consistent way to download subsets of OOI data sets in common file formats and make graphs and maps.

Key Features:

- Single data request format

- Common file format (with many file type options) and common time format

- RESTFul API for scripted data requests

- More information and user manuals available via the landing page

\section{Raw Data Archive}

https://rawdata.oceanobservatories.org/files

All raw data from all platforms and instruments are stored by OOI, including hydrophones, HD video, and seismometers. A subset of the total stored raw data is delivered via the Raw Data Archive, which allows users to perform their own analyses using their own scripts or software, and to permit operators to confirm status of deployed instrumentation.

Key Features:

- "Raw" indicates data as they are received directly from an instrument, in instrument-specific format

- The archive is a mirror of the repository where all raw data enter the system

- Data in the online archive may be removed for space reasons. These data are never deleted and are available to users upon request. 

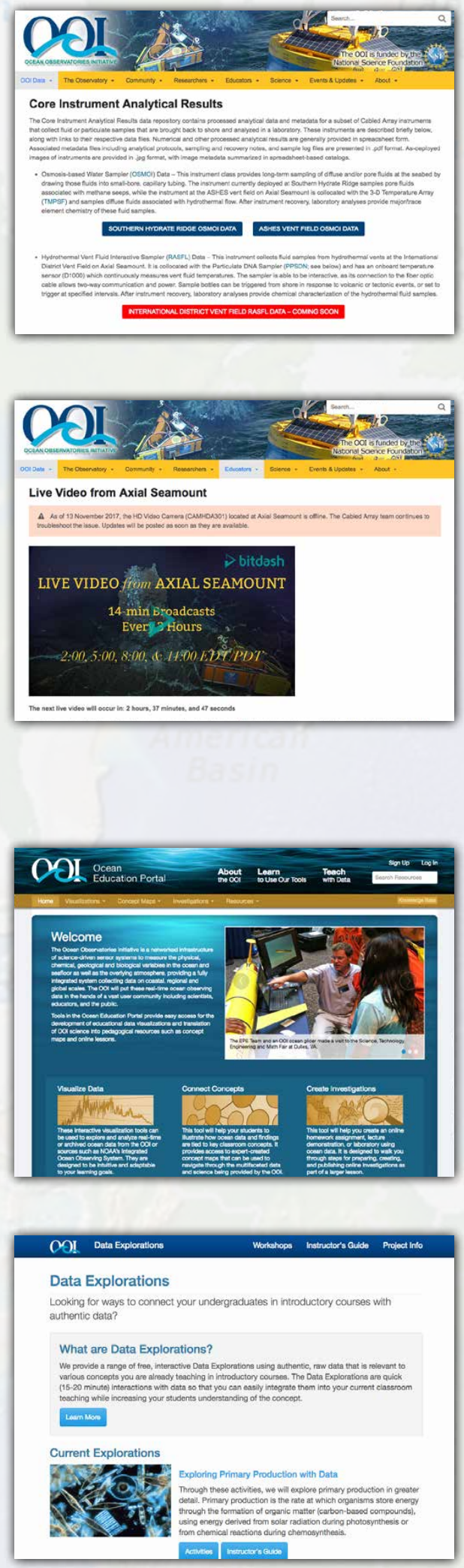

\section{Analytical Data}

http://oceanobservatories.org/core-instrument-analytical-results

The Core Instrument Analytical Results data repository contains processed analytical data and metadata for a subset of Cabled Array instruments that collect fluid or particulate samples and that are brought back to shore and analyzed in a laboratory.

\section{Key Features:}

- Processed analytical results are generally provided in spreadsheet format

- Associated metadata files are presented in .pdf format

- As-deployed images of instruments provided in .jpg format, with image metadata summarized in spreadsheet-based catalogs

\section{Live Video Feed}

http://oceanobservatories.org/streaming-underwater-video

Every three hours from $400 \mathrm{~km}$ off the Oregon coast and $1.6 \mathrm{~km}$ underwater, HD video streams live over the Internet through the OOl's Cabled Array in situ camera system. Video focuses on the $4.3 \mathrm{~m}$ tall actively venting hot spring deposit called "Mushroom" located within the ASHES vent field on Axial Seamount.

Key Features:

- Live video occurs during the hours of 2:00, 5:00, 8:00, and 11:00 EDT \& PDT, for a duration of 14 minutes

- The camera also records continuously for 24 hours on the $10^{\text {th }}$ and $20^{\text {th }}$ of every month, and 72 hours nonstop from the $1^{\text {st }}$ to $3^{\text {rd }}$ of every month, to examine animal behavior, diurnal/tidal cycles, and other changes in hydrothermal flow

\section{OOI Ocean Education Portal}

http://education.oceanobservatories.org

The Ocean Education Portal facilitates access for the development of educational data visualizations and translation of $\mathrm{OOI}$ science into pedagogical resources.

Key Features:

- Data visualization tools prototypes

- Concept mapping tool

- Ontology tool

- Lesson Lab Builder prototype

\section{Data Explorations}

http://education.oceanobservatories.org/explorations

Provides quick (15-20 minute) interactive explorations using authentic OOI data relevant to various concepts taught in introductory oceanography courses. Easily integrated into classroom teaching while increasing students' understanding of key concepts.

Key Features:

- Collection of activities focused on geology, chemistry, and biological productivity

- Pedagogical support (Learning Cycle) to help you frame the data activity in your class lesson.

\section{AUTHORS}

Michael F. Vardaro (vardaro@marine.rutgers.edu) is OOI Data Manager, and Janice McDonnell is Associate Professor, both at Rutgers University, New Brunswick, NJ, USA.

\section{ARTICLE CITATION}

Vardaro, M.F., and J. McDonnell. 2018. Accessing OOI data. Oceanography 31(1):36-37,

https://doi.org/10.5670/oceanog.2018.106. 